\title{
Effects of the Kappa-opioid Receptor Agonist, U69593, on the Development of Sensitization and on the Maintenance of Cocaine Self-administration
}

\author{
Susan Schenk, Ph.D., Brian Partridge, M.S., and Toni S. Shippenberg, Ph.D.
}

Previous studies showed that prior administration of kappa-opioid agonists decreased the development of sensitization to some of the behavioral effects of cocaine. The present study sought to determine whether the development of sensitization to cocaine's reinforcing effects was also sensitive to antagonism by kappa-opioid agonists. During a pretreatment phase, the kappa-opioid agonist, U69593 (0.0 or $0.32 \mathrm{mg} / \mathrm{kg}$ ) was administered prior to (1) 2 daily injections of cocaine $(0.0$ or $20.0 \mathrm{mg} / \mathrm{kg})$, or (2) cocaine or saline administered via a yoking procedure. Cocaine pretreatment decreased the latency to acquisition of cocaine self-administration. However, prior administration of U69593 during the pretreatment phase failed to attenuate the development of this sensitized response to cocaine's reinforcing effect. In other groups, the effect of acute U69593 pretreatment on the maintenance of cocaine selfadministration was examined during a $10 \mathrm{hr}$ session. During training and testing, a stimulus was associated with each self-administered cocaine infusion for one group whereas responding of another group was reinforced by a cocaine infusion alone. On the test day, pretreatment with U69593 $(0.32 \mathrm{mg} / \mathrm{kg})$ decreased responding during each hour of the $10 \mathrm{hr}$ session for the group that was reinforced with cocaine plus the cocaine-associated stimulus. U69593 failed to produce a long-lasting disruption of cocaine selfadministration for rats that were trained and tested without the cocaine-associated stimulus. These data suggest that the acquisition and maintenance of cocaine self-administration are differentially sensitive to manipulations of kappa-opioid systems. Further, the disruption of cocaine self-

administration by U69593 may be due to interactions with mechanisms that underlie facilitative effects of stimuli that have been associated with self-administered cocaine infusions.

[Neuropsychopharmacology 24:441-450, 2001]

(C) 2001 American College of Neuropsychopharmacology. Published by Elsevier Science Inc.
KEY WORDS: Cocaine; Sensitization; Self-administration; Kappa-opioids, U69593

From the Department of Psychology, Texas A\&M University, College Station, TX (SS, BP); and the National Institute on Drug Abuse, Integrative Neuroscience Unit, Baltimore, MD (TSS).

Address correspondence to: Dr. Susan Schenk, Department of Psychology, Texas A\&M University, 230 Psychology Bldg., College Station, TX 77843. Tel.: (979) 845-9504; Fax: (979) 845-4727; E-mail: sxs@psyc.tamu.edu

Received September 23 1999; revised July 25, 2000; accepted August 3, 2000.
Following repeated exposure to cocaine and other stimulants, the behavioral and neurochemical responses to subsequent exposures increase. This sensitized response has been suggested to contribute to the development of compulsive drug-taking that characterizes abuse and to the maintenance of self-administration via the strengthening of stimulus/reward associations (Robinson and Berridge 1993; Shippenberg and Heidbreder 1995). If so, treatments that prevent or attenuate the development of sensitization might be effective adjuncts to the treatment of cocaine addiction.

Preclinical studies have demonstrated the impor- 
tance of the mesocorticolimbic dopamine system in the maintenance of cocaine self-administration. For example, destruction of the ascending dopamine pathways via 6-hydroxydopamine (Roberts et al. 1977) or pretreatment with dopamine antagonists (Caine and Koob 1994; De Wit and Wise 1977) attenuated cocaine selfadministration and shifted the dose-effect curve for cocaine self-administration to the right (Caine and Koob 1994; Schenk et al. 1999). In addition, cocaine has been shown to be self-administered directly into the medial prefrontal cortex (Goeders and Smith 1983) the projection site of the mesocortical dopamine system.

Recent studies have shown that dopamine release is modulated by manipulations of kappa-opioid receptor systems. For example, pretreatment with kappa-opioid receptor agonists inhibited basal DA release in the NAC (Devine et al. 1993; Shippenberg et al. 1994; Spanagel et al. 1992) whereas administration of a k-opioid receptor antagonist increased basal dopamine release (Spanagel et al. 1992). Manipulations of kappa-opioid receptor systems also affect many of the behavioral responses to cocaine. Pretreatment with kappa-opioid receptor agonists attenuated the discriminative stimulus properties (Riberdy et al. 1995; Spealman and Bergman 1992, 1994), conditioned reinforcing effects (Crawford et al. 1995), and self-administration (Glick et al. 1995; Mello and Negus 1998; Negus et al. 1997; Schenk et al. 1999) of cocaine. Further, in an animal model of relapse, U69593 pretreatment attenuated the ability of an experimenter-delivered priming injection of cocaine to reinstate extinguished cocaine-taking behavior (Schenk et al. 1999).

Kappa-opioid agonists also attenuate the sensitized responses that occur following repeated exposure to cocaine and other stimulants. When administered repeatedly with cocaine, the kappa-opioid agonists U50488 or U69593 prevented the cocaine-produced increase in the response of the mesolimbic dopamine system to subsequent cocaine exposures (Heidbreder et al. 1996, 1998) and attenuated the ability of cocaine preexposure to sensitize rats to the conditioned reinforcing and locomotor activating effects of cocaine (Heidbreder et al. 1993, 1995; Shippenberg et al. 1996, 1998).

The present study sought to determine whether pretreatment with the selective kappa-opioid receptor agonist, U69593 (Lahti et al. 1985) would also attenuate the development of sensitization to the reinforcing effects of cocaine and/or interfere with the maintenance of cocaine self-administration. The development of sensitization was assessed by measuring the latency to acquisition of cocaine self-administration following pretreatment. This latency measure is inversely related to cocaine dose (Schenk et al. 1991, 1993, 1999) and, in previous studies, it was demonstrated that pretreatment with cocaine decreased the latency to acquisition of self-administration (Horger et al. 1990; Schenk and Partridge 2000). For some groups in the present study the effect of U69593 on the development of this sensitized response was determined. The effect of U69593 pretreatment on the maintenance of cocaine self-administration was measured in other groups.

\section{METHOD}

\section{Subjects}

Male Sprague-Dawley rats (Harlan, TX) weighing 325-350 g were used. They were housed individually in hanging polycarbonate cages. The humidity and temperature controlled colony at Texas A\&M University was kept on a 12:12 hr light:dark cycle with lights on at 0800. Food and water were freely available except during testing. Principles of laboratory animal care were followed (NIH publication NO. 85-23, rev. 1985).

\section{Surgery}

A chronic indwelling Silastic catheter was implanted in the right jugular vein. Briefly, the rats were deeply anesthetized with ketamine $(60.0 \mathrm{mg} / \mathrm{kg})$ and pentobarbital $(20.0 \mathrm{mg} / \mathrm{kg})$. The external jugular vein was isolated, the catheter was inserted and the distal end (22 ga stainless steel tubing) was passed subcutaneously to an exposed portion of the skull where it was fixed to embedded jeweler's screws with dental acrylic. Each day, the catheters were infused with $0.1 \mathrm{ml}$ of a sterile saline solution containing heparin $(1.25 \mathrm{U} / \mathrm{ml})$, penicillin G Potassium $(250,000 \mathrm{U} / \mathrm{ml})$, and streptokinase $(8000 \mathrm{IU} / \mathrm{ml})$ to prevent infection and the formation of clots and fibroids. The rats were allowed 5 days post surgery for recovery. Sample sizes for each group are indicated in Table 1 and represent the number of subjects (generally $75-80 \%$ ) that completed testing with patent catheter lines. Patency was confirmed by the immediate loss of the righting reflex produced by an infusion of sodium pentobarbital (15.0-20.0 mg/ $\mathrm{kg}$, iv) following the completion of testing.

Table 1. Summary of Pretreatment Groups for Tests of the Effects of U69593 and Cocaine on the Acquisition of Cocaine Self-administration

\begin{tabular}{llr}
\hline U69593 Dose & Cocaine Dose & $\boldsymbol{n}$ \\
\hline Vehicle & Saline & 21 \\
$0.32 \mathrm{mg} / \mathrm{kg}$ & Saline & 14 \\
Vehicle & $2 \times 20$ & 9 \\
$0.32 \mathrm{mg} / \mathrm{kg}$ & $2 \times 20$ & 8 \\
$2 \times 0.16 \mathrm{mg} / \mathrm{kg}$ & $2 \times 20$ & 17 \\
- & Contingent cocaine & 12 \\
Vehicle & Yoked Saline & 12 \\
Vehicle & Yoked Cocaine & 11 \\
$0.32 \mathrm{mg} / \mathrm{kg}$ & Yoked Cocaine & 11 \\
\hline
\end{tabular}




\section{Apparatus}

Self-administration testing was carried out in operant chambers (Med Associates, ENV-001) equipped with 2 levers. Depression of one lever (the active lever) resulted in an intravenous infusion of cocaine $\mathrm{HCl}$, dissolved in sterile physiological saline and heparin (3 U/ $\mathrm{ml}$ ). Depression of the other lever (the inactive lever) was without programmed consequence. Drug delivery and data acquisition were controlled by the OPN software package (Spencer and Emmett-Oglesby 1985). Cocaine deliveries were made via mechanical pumps (Razel Model A with $1 \mathrm{rpm}$ motor equipped with $20.0 \mathrm{ml}$ syringes) in a volume of $0.1 \mathrm{ml}$ over $12.0 \mathrm{sec}$. For all groups except one (see below) the illumination of a stimulus light located above the active lever was coincident with drug delivery.

\section{Procedure: Effects of Cocaine and U69593 Pretreatment on the Acquisition of Self-administration}

Pretreatment Phase. Separate groups of rats received cocaine preexposure through either experimenter-administered intraperitoneal injections or via intravenous infusions delivered according to a yoking procedure. Table 1 presents a summary of the various conditions and the final sample sizes for each group.

On each of 5 pretreatment days, rats in the experimenter-delivered cocaine groups received 2 daily intraperitoneal injections of $20.0 \mathrm{mg} / \mathrm{kg}$ cocaine or vehicle separated by $1 \mathrm{hr}$. Each injection was in a volume of 1.0 $\mathrm{ml} / \mathrm{kg}$. This protocol was used since we have previously determined that it resulted in a decreased latency to cocaine self-administration (Schenk and Partridge 2000). Additional groups of rats received U69593 as a single bolus injection $(0.32 \mathrm{mg} / \mathrm{kg}, \mathrm{SC}) 15 \mathrm{~min}$ prior to the first of the 2 daily experimenter-administered injections of cocaine or as 2 injections $(0.16 \mathrm{mg} / \mathrm{kg}$ each injection, SC) with each administered $15 \mathrm{~min}$ prior to each of the 2 cocaine injections. This dose of U69593 was chosen since it produced a decrease in self-administration of low doses of cocaine in a previous study (Schenk et al. 1999). An additional group received an injection of U69593 $(0.32 \mathrm{mg} / \mathrm{kg})$ followed by an injection of saline during the 5-day pretreatment phase. All pretreatment injections were administered in the animal colony and the rats were immediately returned to the home cage following each injection

Other triads of rats received yoked exposure to cocaine during 10 daily 2-hr sessions. One rat from each triad (contingent cocaine) received an infusion of cocaine $(0.25 \mathrm{mg} / \mathrm{kg} /$ infusion) contingent on depression of the active lever, one rat received an infusion of cocaine (yoked cocaine) and one received an infusion of saline (yoked saline) dependent on the responses of the contingent rat. Another group of rats received U69593 $(0.32 \mathrm{mg} / \mathrm{kg})$ in the home cage $15 \mathrm{~min}$ prior to receiving cocaine through the yoking procedure. During the 10day preexposure period, levers were removed from the boxes that housed the rats that received the infusions through the yoking procedure. Occasionally, one of the response-contingent rats developed a leak in the catheter line and was excluded from further testing. The yoked partners of these rats received cocaine or saline during the remaining test days according to the pattern of behavior of an alternate contingent rat.

Acquisition of Cocaine Self-Administration. Tests of the acquisition of cocaine self-administration began 3 days following the last of the pretreatments. Acquisition of cocaine self-administration $(0.25 \mathrm{mg} / \mathrm{kg} / \mathrm{infu}-$ sion) was measured during 8 (experimenter-administered cocaine groups) or 10 (yoked groups) daily $2-\mathrm{hr}$ sessions. This dose of cocaine was chosen since we have found that the average latency to acquisition of selfadministration is 6-7 days and therefore the observation of both increases and decreases in latency to acquisition can be measured. When higher doses of cocaine are used in these acquisition studies, latency to acquisition is shorter and it is difficult to measure further decreases as a result of pretreatment. When lower doses of cocaine are used, the latency to acquisition of selfadministration is very long and a significant number of subjects fail to acquire self-administration within a 20day test period (Schenk et al. 1991, 1993). Therefore, the use of the $0.25 \mathrm{mg} / \mathrm{kg} /$ infusion dose allowed efficient measurement of increases or decreases in latency to acquisition following pretreatment.

On these days, the session began with an experimenter administered priming injection of cocaine $(0.25$ $\mathrm{mg} / \mathrm{kg}$ ). Thereafter, infusions were delivered according to an FR-1 schedule of reinforcement by depression of the active lever. Inactive lever responses were recorded but had no programmed consequences.

\section{Data Analysis}

Individual ANOVAs (Day $\times$ Pretreatment) compared the number of active lever responses produced on each day of testing for (1) the vehicle/saline and vehicle/cocaine preexposure groups, (2) the vehicle/cocaine and U69593/cocaine preexposure groups and (3) the vehicle/yoked saline, vehicle/yoked cocaine and U69593/yoked cocaine preexposure groups.

The number of days to acquisition of cocaine selfadministration was also compared for the various groups. The criterion for acquisition of self-administration was (1) a minimum of 30 active lever responses per session; (2) a minimum of 2:1 ratio active:inactive lever responses. Acquisition was defined as the first day that this criterion was met for 3 consecutive days and was 
determined for each subject. Since some subjects from each group failed to acquire self-administration within the period tested, the median number of days to acquisition was determined and was compared using a Mann Whitney U test.

\section{Effects of Cocaine and U69593 Pretreatment on Maintenance of Self-administration}

Training. Each daily 2-hr session began with an experimenter delivered "prime" of cocaine $(0.50 \mathrm{mg} / \mathrm{kg} /$ infusion). Thereafter, cocaine $(0.50 \mathrm{mg} / \mathrm{mg} /$ infusion $)$ was delivered on a continuous reinforcement schedule by depression of the active lever. Some rats received a light stimulus paired with each infusion of cocaine. Others received cocaine infusions without the associated light stimulus. This higher dose of cocaine was used since our preliminary studies indicated that a large number of subjects in the "no light" group failed to acquire self-administration of the lower dose of cocaine within the 10-day acquisition period. Responses on both the active and inactive levers were recorded. The criteria for acquisition were (1) at least 30 responses on the active lever and (2) an active to inactive response ratio of at least 2:1. Following acquisition, the schedule of reinforcement was increased to FR5 for at least seven days prior to testing. Self-administration behavior was considered stable when there was less than $20 \%$ variation in the number of responses produced across 3 days of testing.

Test Day. On the test day, the session length was increased to $10 \mathrm{hr}$ and the effect of U69593 (0.0 or 0.32 $\mathrm{mg} / \mathrm{kg}, \mathrm{SC}$ ) on responding during each hour of the session was measured. For rats that had been trained to self-administer cocaine with the associated light stimulus $(n=10)$ completion of the FR-5 schedule was reinforced by the presentation of a cocaine-associated light stimulus during each $12.0 \mathrm{sec}$ cocaine infusion. For rats trained without the cocaine-associated light stimulus $(n=$ 8) completion of the FR-5 schedule was reinforced by a $12.0 \mathrm{sec}$ infusion of cocaine alone. Half of each group of rats was administered the vehicle injection $15 \mathrm{~min}$ prior to the 10-hr test and the other half was administered $0.32 \mathrm{mg} / \mathrm{kg}$ U69593 $15 \mathrm{~min}$ prior to the 10-hr test.

\section{Data Analysis}

ANOVAs (Dose U69593 $\times$ Time) were conducted on the number of responses produced during each hour of the 10-hr session. Individual ANOVAs were conducted on the data from the rats that were trained and tested with and without the cocaine-associated light stimulus.

Drugs. Cocaine $\mathrm{HCl}$ (National Institute of Drug Abuse) was dissolved in sterile physiological saline. Intravenous infusions were delivered in a volume of 100 $\mathrm{ul}$ and intraperitoneal injections were delivered in a volume of $1.0 \mathrm{ml} / \mathrm{kg}$. U69593 (National Institute of Drug Abuse) was dissolved in 20\% propylene glycol in sterile water and was administered SC in a volume of $1.0 \mathrm{ml} / \mathrm{kg}$. All drug weights refer to the salt.

\section{RESULTS}

\section{Effect of Cocaine and U69593 Preexposure on the Acquisition of Cocaine Self-administration}

Figure 1 shows the mean number of active lever responses produced on each of 8 days of testing of rats that had previously received the 5-day pretreatment regimens. The top panel shows the effect of cocaine or saline pretreatment for rats that received the U69593 ve-

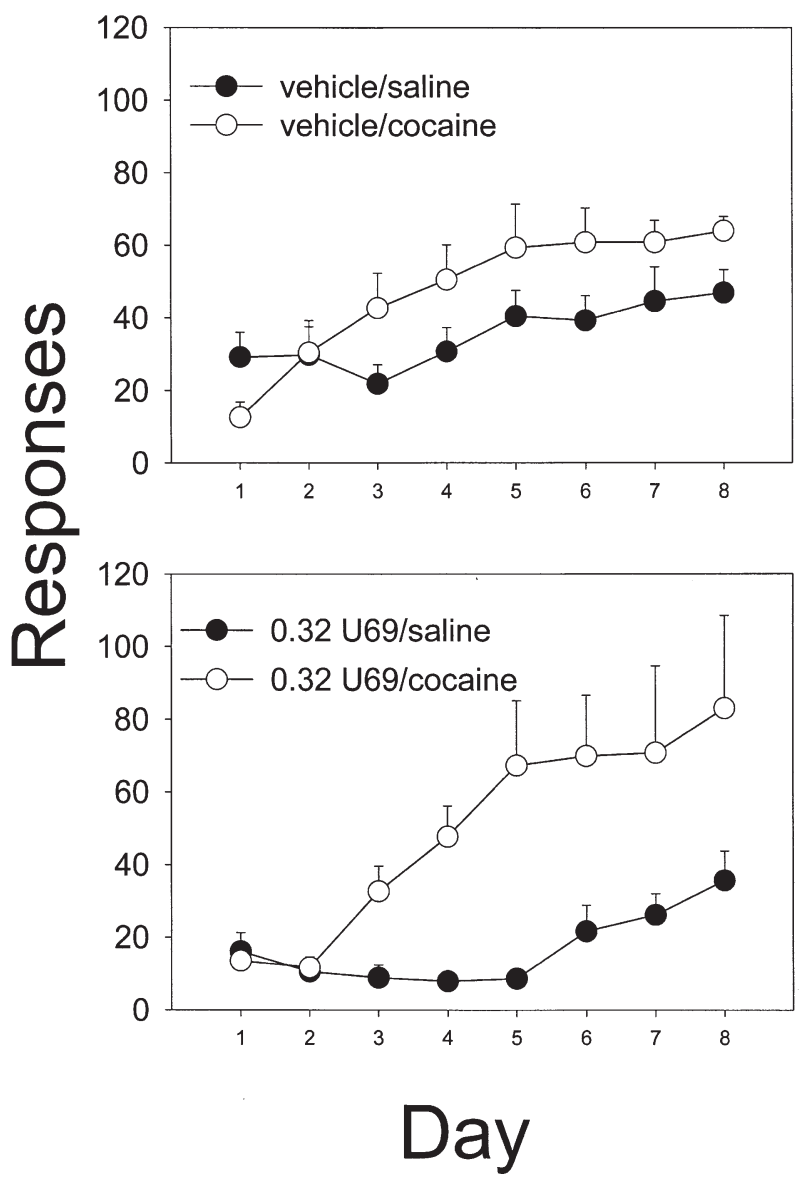

Figure 1. Number of responses produced during each daily 2 hr self-administration session following pretreatment with the U69593 vehicle prior to cocaine or saline (top panel) or $0.32 \mathrm{mg} / \mathrm{kg}$ U69593 prior to cocaine or saline (bottom panel). The 5 day pretreatment consisting of 2 daily injections of $20.0 \mathrm{mg} / \mathrm{kg}$ increased the number of active lever responses produced during the latter days of testing. U69593, administered prior to each of the two cocaine injections during pretreatment failed to attenuate the ability of cocaine to increase responding. 
hicle during pretreatment and the bottom panel shows the effect of cocaine or saline pretreatment for rats that received the single daily injection of $0.32 \mathrm{mg} / \mathrm{kg}$ U69593 during pretreatment.

Regardless of U69593 treatment, cocaine pretreated groups produced a greater number of responses during the latter days of testing when compared to responses produced by rats that received saline during pretreatment. For the rats that received the U69593 vehicle (top panel) prior to the cocaine injections during pretreatment, a repeated measures ANOVA (Pretreatment $x$ Day) on the active lever responses revealed a main effect of Day $[\mathrm{F}(7,196)=11.096, p<.001]$ and an interaction between Day and Pretreatment $[F(7,196)=3.192, p=.006]$. For the rats that received $0.32 \mathrm{mg} / \mathrm{kg}$ U69593 (bottom panel) prior to the cocaine injections, the ANOVA revealed a main effect of Day $[\mathrm{F}(7,140)=13.007, p<.001]$, Group $[\mathrm{F}(1,20)=10.622, p=.004]$ and an interaction $[F(7,140)=5.627, p=.006]$. Similar effects were produced in the group that received U69593 as 2 daily injections of $0.16 \mathrm{mg} / \mathrm{kg}$ (data not shown).

Figure 2 shows the median number of days to acquisition of cocaine self-administration following pretreatment with the various U69593/cocaine combinations. Rats that received the pretreatment regimen consisting of vehicle/cocaine acquired cocaine self-administration with a shorter latency than rats that received vehicle/saline pretreatment $(p=0.042)$. Pretreatment with U69593 as either a single injection of $0.32 \mathrm{mg} / \mathrm{kg}$ administered $15 \mathrm{~min}$ prior to the first of the cocaine injections or as 2 injections of $0.16 \mathrm{mg} / \mathrm{kg}$ administered 15 min prior to the each of the two daily experimenteradministered injections of cocaine failed to alter the ability of cocaine to decrease the latency to acquisition of cocaine self-administration.

Figure 3 shows the number of active lever responses produced on each of 10 days of testing following pretreatment with vehicle, cocaine or U69593 plus cocaine during the yoking procedure. The vehicle-exposed group produced fewer responses particularly during the early days of testing. A repeated measures analysis (Group $\times$ Day) on the active lever responses revealed a significant effect of Group $[\mathrm{F}(2,31)=4.183, p=.025]$ and Day $[\mathrm{F}(9,279)=$ $10.263, p<.001]$. Subsequent analyses compared responding produced by the group that received vehicle/ saline to responding produced by the group that received vehicle/ cocaine or U69593/cocaine during pretreatment. Regardless of whether $\mathrm{U} 69593[\mathrm{~F}(1,21)=7.1523, p=.014]$ or vehicle $[\mathrm{F}(1,21)=5.405, p=.03]$ was administered prior to cocaine, responses were higher for the rats that received cocaine pretreatment.

Figure 4 shows the median number of days to acquisition of cocaine self-administration following pretreatment with U69593 prior to cocaine or saline delivered during the yoking period. Rats that received the pretreatment regimen consisting of a vehicle injection followed by yoked delivery of cocaine acquired cocaine self-administration with a shorter latency than rats that received a vehicle injection followed by yoked delivery of saline during pretreatment $(p=.004)$. Pretreatment with U69593 administered 15 min prior each of the 10 yoking sessions failed to alter the ability of cocaine to
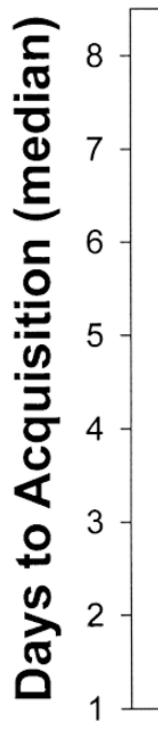

\section{U69593 dose}

0.0

0.32

0.0

0.32

$0.16 \times 2$
Figure 2. Median number of days to achieve criterion for acquisition of cocaine selfadministration for the groups that received various combinations of U69593 and cocaine during the pretreatment phase. Cocaine decreased the latency to acquisition of cocaine selfadministration but this sensitized effect was not attenuated by prior administration of U69593.

\section{$\begin{array}{llllll}\text { Cocaine dose } & 0.0 & 0.0 & 2 \times 20 & 2 \times 20 & 2 \times 20\end{array}$}




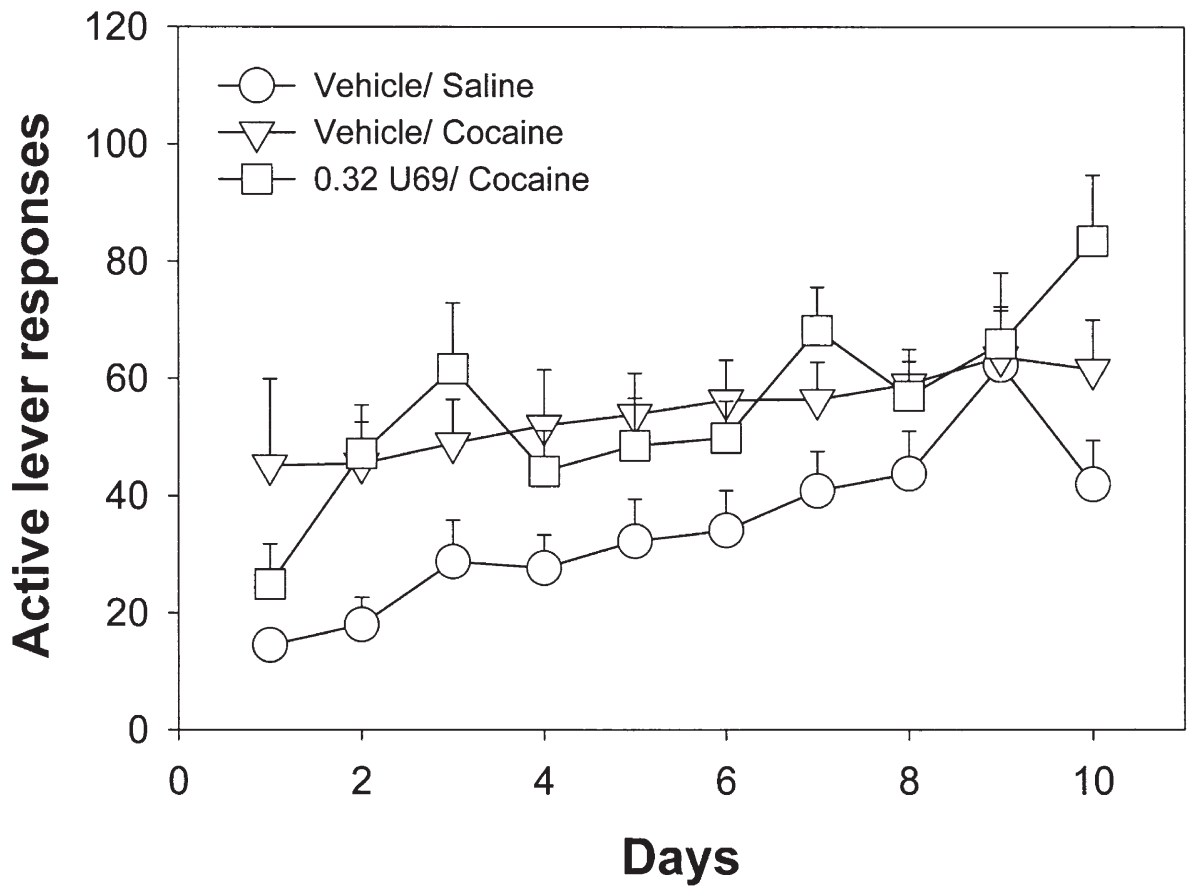

Figure 3. Number of responses produced during each of 10 daily 2 hr sessions following pretreatment. Rats received pretreatment via a yoking procedure that delivered infusions according to the behavior of a self-administering rat. One group received a vehicle injection prior to yoked cocaine delivery, one received a vehicle injection prior to yoked saline delivery and one received an injection of U69593 (0.32 $\mathrm{mg} / \mathrm{kg}$ ) prior to yoked cocaine delivery. Rats that received cocaine via the yoking procedure responded at higher rates than the yoked saline group but this increased rate of responding was not decreased by prior administration of U69593.

decrease the latency to acquisition of cocaine self-administration.

\section{Maintenance of Cocaine Self-administration}

Figure 5 shows the effect of U69593 (0.00 or $0.32 \mathrm{mg}$ / $\mathrm{kg}$ ) upon responding for cocaine during each hour of the 10-hr self-administration session. The top panel shows the data from rats that were trained to self-administer cocaine with an associated light stimulus and the bottom panel shows the data from rats that were trained to self-administer cocaine without the associated light stimulus.

Control rats from the groups that were reinforced by

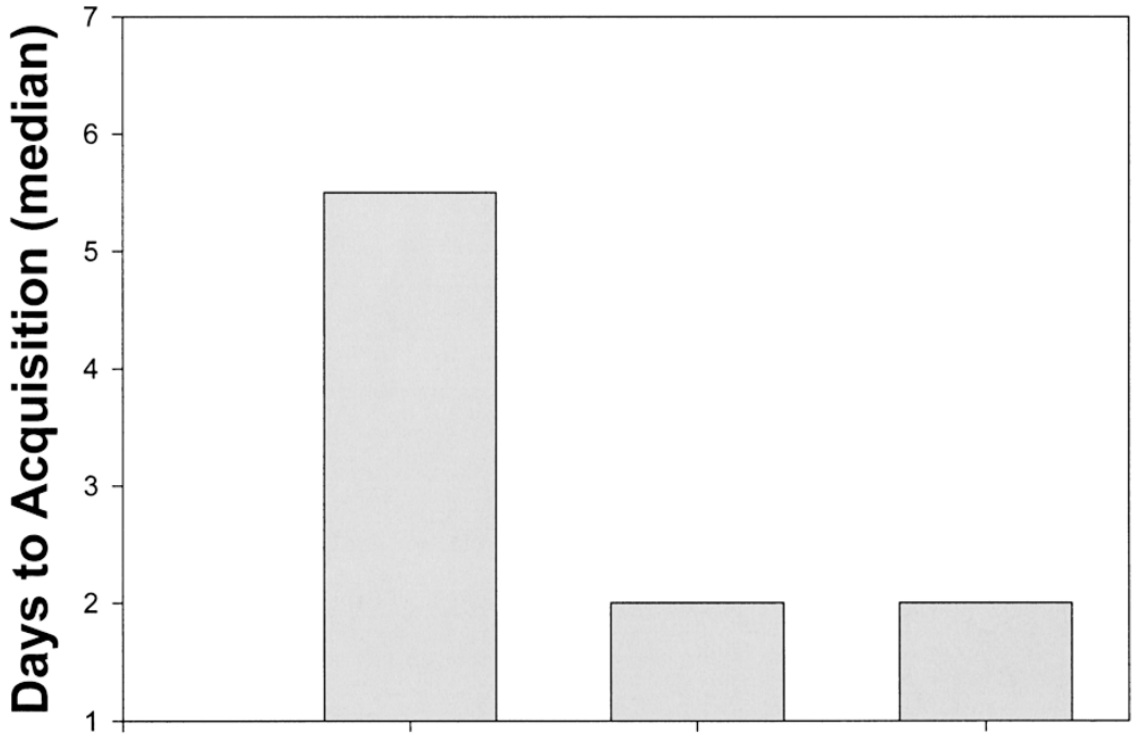

Figure 4. Number of days to achieve criterion for acquisition of cocaine self-administration for the groups that received various combinations of U69593 and cocaine during the yoking that comprised the pretreatment phase. Cocaine pretreatment decreased the latency to acquisition of cocaine self-administration but this sensitized effect was not attenuated by prior administration of U69593. 


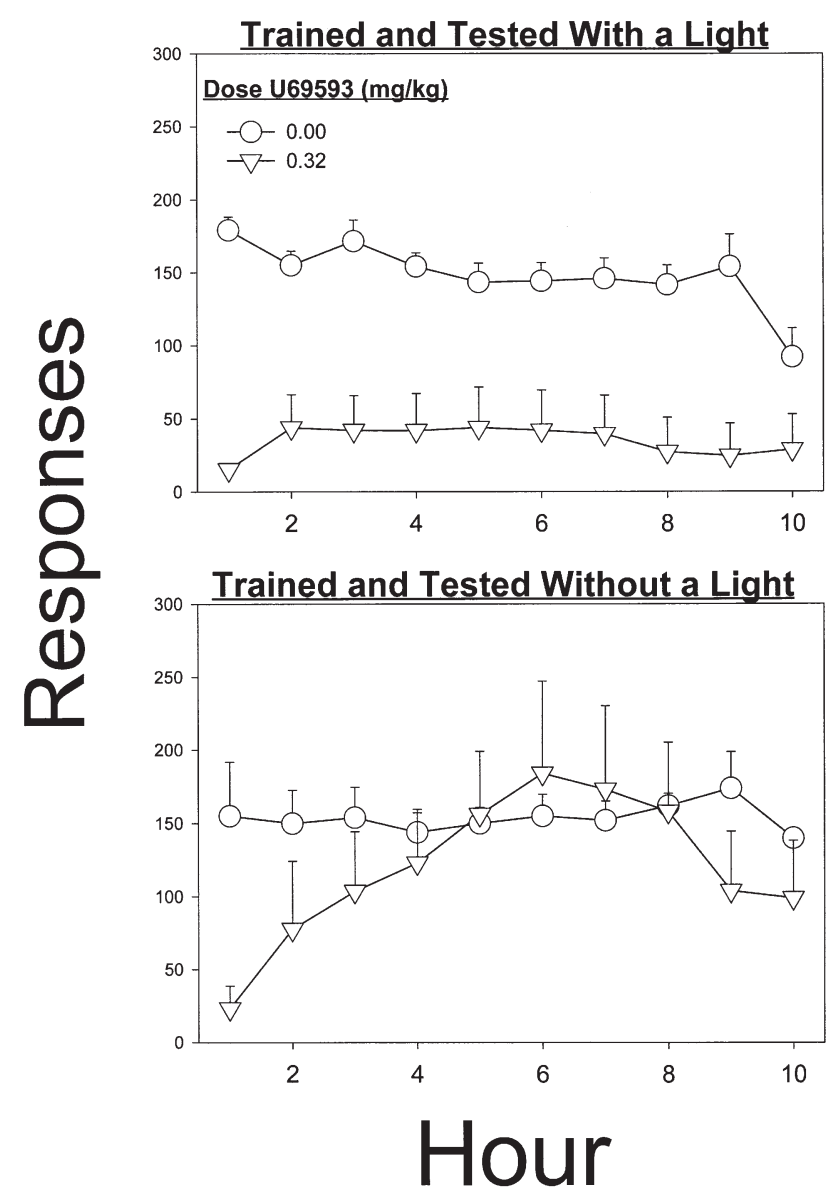

Figure 5. Number of active lever responses produced during each hour of a $10 \mathrm{hr}$ self-administration session $(0.5 \mathrm{mg} /$ $\mathrm{kg} /$ infusion) for rats that received prior administration of U69593 (0.0 or $0.32 \mathrm{mg} / \mathrm{kg}$ ). Top panel shows the data from rats that were trained and tested with a light stimulus that was illuminated during each cocaine infusion. Bottom panel shows the data from rats that were trained and tested without a light stimulus illuminated during each cocaine infusion. U69593 decreased responding of rats trained and tested under both conditions during the first $2 \mathrm{hrs}$ of testing. However, decreases in responding during the subsequent hours of the test were produced by U69593 only when it was administered to rats that were trained and tested with a cocaine-associated light stimulus.

cocaine/light pairings (top panel) exhibited a high rate of responding and responses were evenly spaced throughout the session, with the exception of a decrease in responding during hour 10 . Pretreatment with 0.32 $\mathrm{mg} / \mathrm{kg}$ U69593 produced a marked decrease in the number of responses. An ANOVA (Dose U69593 $\times$ Time) revealed a significant effect of Dose U69593 $[\mathrm{F}(1,10)=10.990, p=.008]$. In fact, of the 5 rats tested, 3 produced fewer than 10 responses per hour following administration of U69593.

Control rats from the group that was reinforced by cocaine without the associated light cue (bottom panel) also produced a high number of responses per hour and the number of responses was comparable to the group that was reinforced with the cocaine/light pairings. Pretreatment with $0.32 \mathrm{mg} / \mathrm{kg}$ U69593 produced an initial decrease in responding. However, the decrease in responding was transient and response rates returned to control levels with continued testing. An ANOVA (Dose U69593 $\times$ Time) failed to reveal a significant effect of U69593 Dose $[\mathrm{F}(1,8)=0.889, \mathrm{NS}]$ or a significant effect of Time $[F(9,72)=0.889, \mathrm{NS}]$. However, a significant interaction $[\mathrm{F}(9,72)=2.031, p=.048]$ was obtained. Tukey post-hoc comparisons revealed that the decrease in responding produced during hours 1 and 2 of the session following pretreatment with 0.32 $\mathrm{mg} / \mathrm{kg}$ U69593 was significant $(p<.05)$.

\section{DISCUSSION}

As we have previously reported (Horger et al. 1990; Schenk and Partridge 2000), the latency to acquisition of cocaine self-administration was decreased by prior exposure to cocaine. These findings are consistent with the results of other studies that have documented sensitization to the reinforcing properties of drugs following stimulant preexposure (Horger et al. 1991, 1992; Piazza et al. 1989, 1990). The decreased latency to acquisition of cocaine self-administration produced by cocaine preexposure was not, however, reversed by prior administration of U69593.

The failure of U69593 to attenuate the development of sensitization is not likely due to inadequate dosing or a short duration of action of U69593. We have previously found that a dose of $0.32 \mathrm{mg} / \mathrm{kg}$ U69593 administered prior to a cocaine self-administration session decreased responding for longer than $2 \mathrm{hrs}$ following the injection (Schenk et al. 1999). A long-lasting effect of this dose of U69593 was also demonstrated in the present study when responding maintained by cocaine was decreased for the entire 10-hr self-administration session.

Other studies have shown that the development of sensitization to the conditioned reinforcing properties of cocaine was attenuated by co-administration of U69593 (Heidebreder et al. 1998; Shippenberg et al. 1996, 1998). Generally, lower doses of U69593 (0.04-0.16 $\mathrm{mg} / \mathrm{kg}$ ) were repeatedly administered during the pretreatment phase of those studies, which raises the possibility that tolerance to the effects of U69593 resulted from the higher dose exposures used in the present study. If so, the group that received U69593 alone during pretreatment would have been expected to also be sensitized to cocaine as a result of a decrease in the inhibitory influence of kappa-opioid systems. The latency to acquisition of cocaine self-administration for the group that received repeated exposure to U69593 alone, 
however, was comparable to the latency to acquisition of the rats that received pretreatment with vehicle. Thus, it is unlikely that the failure of U69593 to attenuate cocaine-produced sensitization reflects tolerance that developed during preexposure. Rather, the data suggest that the development of sensitization to the primary reinforcing effect of cocaine is not modulated by kappa-opioid systems.

These negative findings were surprising since other studies have indicated that kappa-opioid agonists attenuate the development of sensitization to cocaine's conditioned reinforcing properties, effects that have been hypothesized to contribute to the development of self-administration (Robinson and Berridge 1993). The differential effects of U69593 on the development of sensitization to the conditioned and primary reinforcing effects of cocaine argue against the idea that sensitization represents a generalized drug-produced facilitation of associative learning (Harmer and Phillips 1999; Taylor and Horger 1999) and suggest that the development of self-administration occurs independent of the development of stimulus/reward associations.

A number of studies have implicated mechanisms in the amygdala in the formation and expression of stimulus/reward associations (Everitt and Robbins 1992; Robbins et al. 1989). For example, excitotoxic lesions of the amygdala blocked the ability of cocaine to produce place conditioning (Brown and Fibiger 1993). Specific lesions of the basolateral nucleus (BLA) decreased sucrose-produced place conditioning (Everitt et al. 1991) and decreased the ability of a stimulus predictive of reward to elicit approach behavior (Burns et al. 1993). Intra-amygdaloid infusions of amphetamine, and to a lesser extent, cocaine, supported the development of a conditioned place preference (O'Dell et al. 1999), although these effects were manifest to a greater extent when the infusions were restricted to the central nucleus. Of particular relevance to the development of sensitization, infusions of amphetamine into the basolateral nucleus potentiated the subsequent development of reward/stimulus associations and facilitated the acquisition of discriminative approach behavior (Hitchcott et al. 1997). Primarily as a result of these findings, it has been suggested that the development of stimulus-reward associations and sensitization to the conditioned reinforcing effects of drugs are due to repeated activation of mesoamygdaloid dopaminergic projections (Harmer and Phillips 1999; Hitchcott et al. 1997).

A lesion of the BLA failed to attenuate the acquisition of self-administration (Whitelaw et al. 1996), which supports the idea that mechanisms underlying the development of stimulus/reward associations and the acquisition of self-administration can be dissociated. The failure of U69593 to alter the development of sensitization to cocaine's primary reinforcing effects might re- flect a selective effect on those processes within the amygdala that underlie the development of conditioned but not primary reinforcement.

Once stimulus/reward associations have been established, the continued presentation of a cocaine-associated stimulus becomes important to the maintenance of self-administration. The important contribution of conditioned stimuli is illustrated by the disruption of cocaine self-administration that occurred following removal of a stimulus that had been association with self-administered cocaine infusions during training (Arroyo et al. 1998; Goldberg et al. 1979; Panlilio et al. 1996; Rinaldi and Roberts 1996).

Of interest, maintenance of self-administration that is associated with conditioned stimuli is dependent on mechanisms in the amygdala. Thus, an excitotoxic lesion of the BLA disrupted the ability of conditioned stimuli to maintain responding on a second order schedule of reinforcement (Whitelaw et al. 1996) and attenuated the ability of cues associated with self-administered cocaine to reinstate extinguished cocaine-taking behavior (Meil and See 1997). This might explain the ability of U69593 to disrupt the maintenance of cocaine self-administration even though the development of sensitization was unaffected.

U69593 was, however, relatively ineffective in decreasing self-administration for the group that had been trained and tested without the cocaine-associated light stimulus. These findings suggest that the maintenance of cocaine self-administration during long sessions is comprised of a kappa-opioid sensitive mechanism that is restricted to self-administration that has been established with the presentation of cocaine-associated stimuli. The selective effects of U69593 on the maintenance of responding in the presence of a conditioned stimulus may reflect an attenuation of the expression of reward/ stimulus associations.

An effect of U69593 in the BLA might explain the selective effects of pretreatment on the development of sensitization to cocaine-produced place conditioning and the common effects on the expression of cocaine's conditioned (Crawford et al. 1995) and primary (Glick et al. 1995; Negus et al. 1997; Schenk et al. 1999; present data) reinforcing effects. It is particularly relevant that cocaine self-administration was attenuated by acute pretreatment with U69593 only for rats that had been trained to self-administer cocaine with an associated stimulus. The relative ineffectiveness of U69593 for rats that had been trained to selfadminister cocaine without the associated stimulus is consistent with the hypothesis that U69593 attenuates the facilitative effects of conditioned stimuli associated with primary rewards. Further, these findings suggest that self-administration for rats that had been trained with a conditioned stimulus may be dependent on different factors and substrates than self- 
administration for rats that had received training without the associated stimulus.

\section{ACKNOWLEDGMENTS}

This research was supported by DA 10084 .

\section{REFERENCES}

Arroyo J, Markou A, Robbins TW, Everitt BJ (1998): Acquisition and maintenance of intravenous cocaine self-administration under a second-order schedule of reinforcement in rats: Effects of conditioned cues and continuous access to cocaine. Psychopharmacology 140: 331-344

Brown EE, Fibiger HC (1993): Differential effects of excitotoxic lesions of the amygdala on cocaine-induced conditioned locomotion and conditioned place preference. Psychopharmacology 113:123-130

Burns LH, Robbins TW, Everitt BJ (1993): Differential effects of excitotoxic lesions of the basolateral amygdala, ventral subiculum and medial prefrontal cortex on responding with conditioned reinforcement and locomotor activity potentiated by intraaccumbens infusions of d-amphetamine. Behav Brain Res 115:516-528

Caine SB, Koob GF (1994): Effects of dopamine D-1 and D-2 antagonists on cocaine self-administration under different schedules of reinforcement in the rat. J Pharmacol Exp Ther 270:209-218

Crawford CA, McDougall SS, Bolanos CA, Hall S, Berger SP (1995): The effects of kappa agonist U50,488 on cocaineinduced conditioned and unconditioned behavior and Fos immunoreactivity. Psychopharmacology 120:392399

De Wit H, Wise RA (1977): Blockade of cocaine reinforcement in rats with the dopamine receptor blocker pimozide, but not with the noradrenergic blockers phentolamine or phenoxybenzamine. Can J Psychol 31:195

Devine DP, Leone P, Pocock D, Wise RA (1993): Differential involvement of ventral tegmental $\mathrm{mu}$, delta and kappa opioid receptors in modulation of basal mesolimbic dopamine release: in-vivo microdialysis studies. J Pharmacol Exp Therap 266:1236-1246

Everitt BJ, Robbins TW (1992): Amygdala-ventral striatal interactions and reward-related processes. In: Aggleton JP (ed), The Amygdala: Neurobiological Aspects of Emotion, Memory and Mental Dysfunction. New York, Wiley-Liss, pp 401-430

Everitt BJ, Morris KA, O’Brien A, Robbins TW (1991): The basolateral amygdala-ventral striatal system and conditioned place preference: further evidence of limbic-striatal interactions underlying reward-related processes. Neuroscience 42:1-18

Glick SD, Maisonneuve IM, Raucci J, Archer S (1995): Kappa-opioid inhibition of morphine and cocaine selfadministration in rats. Brain Res 681:147-152

Goeders NE, Smith JE (1983): Cortical dopaminergic involvement in cocaine reinforcement. Science 221:773775
Goldberg SR, Spealman RD, Kelleher RT (1979): Enhancement of drug-seeking behavior by environmental stimuli associated with cocaine or morphine injections. Neuropharmacol 18:1015-1017

Harmer CJ, Phillips GD (1999): Enhanced dopamine efflux in the amygdala by a predictive, but not a non-predictive, stimulus: Facilitation by prior repeated d-amphetamine. Neuroscience 90:119-130

Heidbreder CA, Babovic-Voksanovic D, Shoaib A, Shippenberg TS (1995): Development of behavioral sensitization to cocaine: influence of kappa opioid receptor agonists. J Pharmacol Exp Ther 275:150-163

Heidbreder CA, Goldberg SR, Shippenberg TS (1993): The kappa opioid agonist U-69593 attenuates cocaine induced behavioral sensitization in the rat. Brain Res 616:335-338

Heidbreder CA, Thompson AC, Shippenberg TS (1996): Role of extracellular dopamine in the initiation and longterm expression of behavioral sensitization to cocaine. J Pharmacol Exp Ther 278:490-502

Heidbreder CA, Schenk S, Partridge B, Shippenberg TS (1998): Increased responsiveness of mesolimbic and mesostriatal dopamine neurons to cocaine following repeated administration of a selective K-opioid receptor agonist. Synapse 30:255-262

Hitchcott PK, Harmer CJ, Phillips GD (1997): Enhanced acquisition of discriminative approach following intraamygdala d-amphetamine. Psychopharmacology 132: 237-246

Horger BA, Shelton K, Schenk S (1990): Preexposure sensitizes rats to the rewarding effects of cocaine. Pharmacol Biochem Behav 37:707-711

Horger BA, Wellman PJ, Morien A, Davies BT, Schenk S (1991): Caffeine exposure sensitizes rats to the reinforcing effects of cocaine. NeuroReport 2:53-56

Horger BA, Giles MK, Schenk S (1992): Preexposure to amphetamine and nicotine predisposes rats to selfadminister a low dose of cocaine. Psychopharmacology 107:271-276

Lahti RA, Mickelson MM, McCall JM, Vonvoigtlander PF (1985): [3H\}]U-69593 a highly selective ligand for the opioid kappa receptor. Eur J Pharmacol 109:281-284

Meil WM, See RE (1997): Lesions of the basolateral amygdala abolish the ability of drug associated cues to reinstate responding during withdrawal from selfadministered cocaine. Behav Brain Res 87:139-148

Mello NK, Negus SS (1998): Effects of kappa opioid agonists on cocaine- and food-maintained responding by rhesus monkeys. J Pharmacol Exp Ther 286:812-824

Negus SS, Mello NK, Portoghese PS, Lin CE (1997): Effects of kappa-opioids on cocaine self-administration by rhesus monkeys. J Pharmacol Exp Ther 282:44-55

O'Dell LE, Sussman AN, Meyer KL, Neisewander JL (1999): Behavioral effects of psychomotor stimulant infusions into amygdaloid nuclei. Neuropsychopharmacology 20:591-602

Panlilio LV, Weiss SJ, Schindler CW (1996): Cocaine selfadministration increased by compounding discriminative stimuli. Psychopharmacology 125:202-208

Piazza PV, Deminiere JM, Le Moal M, Simon H (1989): Fac- 
tors that predict individual vulnerability to amphetamine self-administration. Science 245:1511

Piazza PV, Deminiere JM, Le Moal M, Simon H (1990): Stress and pharmacologically-induced behavioral sensitization increases vulnerability to acquisition of amphetamine self-administration. Brain Res 514:22-26

Riberdy A, Kantak KM, Spealman RD (1995): Modulation of the discriminative stimulus effects of cocaine by the kappa-opioid agonist, U-50,488. Soc Neurosci Abs 21:718

Rinaldi R, Roberts DCS (1996): Initiation, maintenance and extinction of cocaine self-administration with and without conditioned reward. Psychopharmacology 128:89-96

Robbins TW, Cador M, Taylor JR, Everitt BJ (1989): Limbicstriatal interactions in reward-related processes. Neurosci Biobehav Rev 13:155-162

Roberts DCS, Corcoran ME, Fibiger HC (1977): On the role of ascending catecholamine systems in intravenous selfadministration of cocaine. Pharmacol Biochem Behav 6:615-620

Robinson TE, Berridge KC (1993): The neural basis of drug craving: an incentive-sensitization theory of addiction. Brain Res 18:247-291

Schenk S, Horger BA, Peltier, R, Shelton K (1991): Supersensitivity to the reinforcing effects of cocaine following 6-hydroxydopamine lesions to the medial prefrontal cortex in rats. Brain Res 543:227-235

Schenk S, Partridge B (2000): Sensitization to cocaine's reinforcing effects produced by various pretreatment regimens in rats. Pharmacol Biochem Behav 66:765-770

Schenk S, Valdez A, McNamara C, House DT, Higley D, Bankson MG, Gibbs S, Horger BA (1993): Development and expression of sensitization to cocaine's reinforcing properties: role of NMDA receptors. Psychopharmacology 111:332-338

Schenk S, Partridge B, Shippenberg TS (1999): U69593, a kappa opioid receptor agonist, decreases cocaine selfadministration and decreases the ability of cocaine to elicit drug-seeking. Psychopharmacology 144:339-346

Shippenberg, TS, Spanagel R, Heidbreder C (1994): Modulation of mesolimbic dopamine release by endogenous opioids: role in drug-induced sensitization and dependence. In: Louilot A, Durkin T, Spampinato U, Cador M (eds), Monitoring Molecules in Neuroscience, Proceedings of the $6^{\text {th }}$ International Conference On In Vivo Methods, pp 123-125

Shippenberg TS, Heidbreder C (1995): Sensitization to the conditioned rewarding effects of cocaine: pharmacological and temporal characteristics. J Pharmacol Exp Ther 273:808-815

Shippenberg TS, Le Flour A, Thompson C (1996): K-opioid agonists prevent sensitization to the conditioned rewarding effects of cocaine. J Pharmacol Exp Ther 276:545-554

Shippenberg TS, LeFevour A, Thompson AC (1998): Sensitization to the conditioned rewarding effects of morphine and cocaine: Differential effects of the $k$-opioid receptor agonist U69593. Eur J Pharmacol 345:27-34

Spanagel R, Hertz A, Shippenberg TS (1992): Opposing tonically active endogenous opioid systems modulate the mesolimbic dopaminergic pathway. Proc Natl Acad Sci USA 89:2046-2050

Spealman RD, Bergman J (1992): Modulation of the discriminative stimulus effects of cocaine by $\mathrm{mu}$ and kappa-opioids. J Pharmacol Exp Ther 261:607-615

Spealman RD, Bergman J (1994): Opioid modulation of the discriminative stimulus effects of cocaine: comparison of $\mathrm{m}, \mathrm{k}$ and $\mathrm{d}$ agonists in squirrel monkeys discriminating low doses of cocaine. Behav Pharmacol 5:21-31

Spencer DG, Emmett-Oglesby MW (1985): Parallel processing strategies in the application of microcomputers to the behavioral laboratory. Behav Res Meth Instrum 17:294-300

Taylor JR, Horger BA (1999): Enhanced responding for conditioned reward produced by intra-accumbens amphetamine is potentiated after cocaine sensitization. Psychopharmacology 142:31-40

Whitelaw RB, Markou A, Robbins TW, Everitt BJ (1996): Excitotoxic lesions of the basolateral amygdala impair the acquisition of cocaine-seeking behavior under a second-order schedule of reinforcement. Psychopharmacology 127:213-224 